\title{
Interactive comment on "Heterogeneous freezing of super cooled water droplets in micrometre range-freezing on a chip" by Thomas Häusler et al.
}

\section{Anonymous Referee \#2}

Received and published: 14 February 2017

The authors introduce an overview of their new cold-stage-based instrument and some results from the experiments with pure water and several reference materials (Juniper pollen, Birch pollen washing water, Microcline, and Snomax ${ }^{\circledR}$ ). The idea to use "hemispherical cavities with defined diameters" is potentially a smart and effective way to prepare uniformly-sized micrometer droplets. However, I could not find any other significant advances in this technique, as compared with existing cold-stage-based techniques. For example, the application of oil cover (immersion) on droplets placed on a cold stage is already widely-used techniques (e.g., Wright and Petters, 2013; Hader et al., 2014; Peckhaus et al., 2016; Polen et al., 2016). In addition, a significant problem is that despite different droplet sizes and mass concentrations, the authors only use the T50 values to compare their results with the literature data. Thus, it is difficult to judge whether their approach is indeed valid or not. Even if the comparison with the 
literature data is performed appropriately, I would like to recommend to resubmit it to other journals that deal with technical papers.

\section{General Comments}

1) The authors mentioned that "After the etching process, a gold layer (thickness 500 $\mathrm{nm}$ ) was sputtered on top of the pattern, leading to an ice nucleation neutral surface. Tests of an uncoated silicon plate indicated that the silicon itself is IN active. A shift of freezing temperatures of ultrapure water from $-38^{\circ} \mathrm{C}$ to approx. $-20^{\circ} \mathrm{C}$ was found for droplets on the uncoated plate. (Page 5, Lines 24-26)". If this is true, the authors need to show evidence that the use of "gold surface" instead of "silicon surface" indeed plays a crucial role in improving the quality of their freezing experiments. For example, other studies on similar freezing techniques have prepared droplets on a hydrophobic silicon slide and immersed them in oils, such as squalene (Wright and Petters, 2013; Hader et al., 2014; Polen et al., 2016) and silicon oil (Peckhaus et al., 2016). Since these studies also reported that freezing of pure water droplets is limited at temperatures above the homogeneous freezing temperature, I doubt if the types of substrates (gold or silicon) might not be a key issue when using microliter-sized droplets covered with oils.

2) The authors should provide the information on the numbers of droplets and the cooling rate for each experiment.

3) As described by the authors, "Homogeneous nucleation depends on the droplet volume (Vali, 1971). (Page 2, Line 32)". However, the authors compare their freezing experiments with $40 \mu \mathrm{m}$ pure water droplets with the results of different droplet sizes (= 10-20 $\mu \mathrm{m}$; Pruppacher and Klett, 1997). In addition, since the authors note that "The freezing spectra (Figure 7) are well comparable to the extended singular model VS66 as described by Vali (2014). (Page 8, Lines 3-4)", the authors would need to show the values obtained from the extended singular model VS66. Or I would like to suggest to calculate the fice values for $40 \mu \mathrm{m}$ pure water droplets predicted by the classical nucleation theory (e.g., see Murray et al., 2010; Whale et al., 2015; Tobo, 2016). 
4) The comparison of the T50 values obtained from droplets with different sizes and mass concentrations is quite problematic. I strongly suggest to calculate the ice nucleation active site density per unit surface area (ns) and/or $(\mathrm{nm})$ to compare the results from this study and the literature data. Or if the authors want to use the T50 values instead of the ns and/or nm values, they should compare the T50 values at the same droplet sizes (volumes) and mass concentrations. Otherwise, it is difficult for the readers to judge whether the cold-stage-based approaches proposed by the authors are valid or not.

5) To discuss the results from Microcline (Page 8, Lines 14-18), the authors would need to compare the results based on the ns and/or nm values (see "General Comment 4"). In addition, the authors should explain the details of the difference of milling processes between this study and Zolles et al. (2015). Otherwise, I don't know whether "The higher freezing temperature found in our experiment might be due to varied milling parameters. (Page 8, Lines 17-18)".

6 ) It is hard to understand whether the discussion on the results from Snomax ${ }^{\circledR}$ (Page 8, Lines 21-29) are reasonable or not. First, the authors would need to compare the results based on the ns and/or nm values (see "General Comment 4"). In addition, the authors would need to provide the detailed information on the conditions of Snomax ${ }^{\circledR}$ samples used here, since recent studies reported that the ice nucleation properties of Snomax ${ }^{\circledR}$ are considerably unstable and can change dramatically depending on their conditions (Polen et al., 2016).

Specific comments

1) In Abstract, the authors need to explain what "the T10 values" mean.

2) I could not find the descriptions of Figures 1 and 2 in the main text.

3) Page 2, Line 5: ice nuclei (INPs) => ice nucleating particles (INPs)

Printer-friendly version

4) Page 2, Line 28: Demott, 1990; Mohler et al., 2006 => DeMott 1990, Möhler et al., 
5) The authors need to explain what the "V66 model (Page 3, Lines 7)" is.

6) As mentioned by the authors, "Whale et al. (2015) have shown that ultrapure water droplets with a diameter of approx. $1 \mathrm{~mm}$ are often so strongly contaminated with INPs that the homogeneous freezing temperature is not reached and freezing occurs at around $-25^{\circ} \mathrm{C}$ heterogeneously (Page 3, Line 27-29)". On the other hand, recent work reported that despite the use of such large droplet sizes, freezing of pure water droplets placed on a Vaseline layer is limited at temperatures above a homogeneous freezing limit (Tobo, 2016).

7) Section 4.2: I cannot understand why the title of this section is "Snomax ${ }^{\circledR}$ " since the authors describe the results of freezing experiments with Juniper, Birch pollen, Microcline and Snomax ${ }^{\circledR}$. The authors should describe only the results from Snomax ${ }^{\circledR}$ and the other results should be presented in different sections appropriately.

8) Figure 9: Pruppacher et al. (1997) => Pruppacher and Klett (1997)

9) Figure 9: It is a little difficult to understand the difference between "freezing chip" and "water-oil immersion", since the freezing chip also uses oil cover (immersion). Is it correct? If so, I would suggest to use a different wording to avoid misunderstanding.

\section{References}

Hader, J. D., Wright, T. P., and Petters, M. D.: Contribution of pollen to atmospheric ice nuclei concentrations, Atmos. Chem. Phys., 14, 5433-5449, 2014.

Murray, B. J., Broadley, S. L.,Wilson, T.W., Bull, S. J.,Wills, R. H., Christenson, H. K., and Murray, E. J.: Kinetics of the homogeneous freezing of water, Phys. Chem. Chem. Phys., 12, 10380-10387, doi:10.1039/c003297b, 2010.

Polen, M., Lawlis, E., and Sullivan, R. C.: The unstable ice nucleation properties of Snomax ${ }^{\circledR}$ bacterial particles, J. Geophys. Res. Atmos., 121, 11666-11678, 2016.

Printer-friendly version

Discussion paper
Interactive

comment 
Pruppacher, H. R. and Klett, J. D.: Microphysics of clouds and precipitation, Kluwer Academic Publishers, Dordrecht, the Netherlands, 1997.

Tobo, Y.: An improved approach for measuring immersion freezing in large droplets over a wide temperature range, Sci. Rep., 6, 32930, 2016.

Vali, G.: Quantitative evaluation of experimental results on the heterogeneous freezing nucleation of supercooled liquids, J. Atmos. Sci., 28, 402-409, 1971.

comment

Vali, G.: Interpretation of freezing nucleation experiments: singular and stochastic; sites and surfaces, Atmos. Chem. Phys., 14, 5271-5294, 2014.

Whale, T. F., et al.: A technique for quantifying heterogeneous ice nucleation in microlitre supercooled water droplets, Atmos. Meas. Tech., 8, 2437-2447, 2015.

Wright, T, P. and Petters, M. D.: The role of time in heterogeneous freezing nucleation, J. Geophys. Res. Atmos., 118, 3731-3743, 2013.

Zolles, T., Burkart, J., Hausler, T., Pummer, B., Hitzenberger, R., and Grothe, H.: Identification of ice nucleation active sites on feldspar dust particles, Journal of Physical Chemistry A, 119, 2692-2700, 2015.

Interactive comment on Atmos. Chem. Phys. Discuss., doi:10.5194/acp-2017-31, 2017. 